\title{
The Design of Cost Estimating Model of Construction Project: Application and Simulation
}

\author{
Abdelhak Challal, Mohamed Tkiouat \\ Studies and Research Laboratory in Applied Mathematics (LERMA), Mohammed V University Agdal-Mohammadia School \\ of Engineering, Rabat, Agdal Maroc \\ Email: challal@daag.finances.gov.ma; mohamedtkiouat@gmail.com
}

Received May 2, 2012; revised June 11, 2012; accepted July 3, 2012

\begin{abstract}
Construction projects are encountered with serious risks in the completion of the project. One of these risks is the inaccuracy of cost estimate; the project is carried out under conditions of uncertainty, it is whether the over- or underestimate of construction works. This is due to inadequate knowledge of current existing costs, so it leads to a set of difficulties hindering, the smooth progress of the project. Hence, it arises the need to set out a cost estimating model in line with major studies made locally and internationally in terms of estimating methods and a common relationships between various expenses so that the cost estimate would be more realistic
\end{abstract}

Keywords: Estimation; Cost; Project; Construction; Methods; Model

\section{Introduction}

A delay in construction field is a global phenomenon. In Nigeria, Ajanlekoko [1] identified, through questionnaire survey the delay effects in 61 projects. The results demonstrated the frequency of costs overrun; they are caused mainly by the client. Chan and Kumaraswamy [2] studied the delays in construction industry in Hong Kong; they highlighted the fact that a project is commonly acknowledged successful when it is completed on time and within budgetary costs.

According to Faridi and El Sayeh [3], the delays have negative impacts on the project success in terms of time, cost, quality and security.

Jagboro and Aibinu [4] indicated that the contractor and the client are jointly or separately in charge of construction project delay during its completion, the delays can only be minimized by the identification of its causing factors, they also suggest applying reliable methods and proper practices commonly agreed in order to have a proper estimate of costs. Another fact to be reported is that the causes can be controlled during the project life cycle and saving resources can be within reach by having causes identified and monitored.

According to Gkritza [5], the causes are located in the preliminary phases, the causes were reported to be the poor estimation of quantities, design errors, site conditions, the increasing costs for materials and labour (mostly due to inflation) and unanticipated circumstances.

In the construction field, the estimate serves to deter- mine precisely the possible cost to build or modify a building. The estimate is commonly done through plans and quote.

The estimate can take many forms. We can cite one example to illustrate this, let's take the case of the owner, he tries to make simple calculations to check his funding capacity of his budget, and then it is usually an imprecise form of estimate that will be utilized here. On the contrary, the Contractor adopts a very precise estimate for obtaining a contract.

The construction project cost is estimated by the client besides the choices made by project manager while drawing up the design brief.

The budget estimate is a difficult task since it is about anticipating the characteristics of future work and the procedures for conducting the survey. This estimate requires careful consideration because it is about a budget that we will all vote for and negotiate with the concerned Directorates (the Budget Directorate, the Administrative and Financial Affairs Directorate etc...). The usual evolutions of project development must form part of the estimate.

Establishing an accurate estimate is a challenge particularly important. So the client must provide himself with all resources needed to establish the estimate in the best possible conditions and avoid unintended conesquences clearly seen in over- or under estimates (Diagram 1).

In fact, lack of knowledge of realistic estimate of the costs is a source of serious difficulties hindering the pro- 


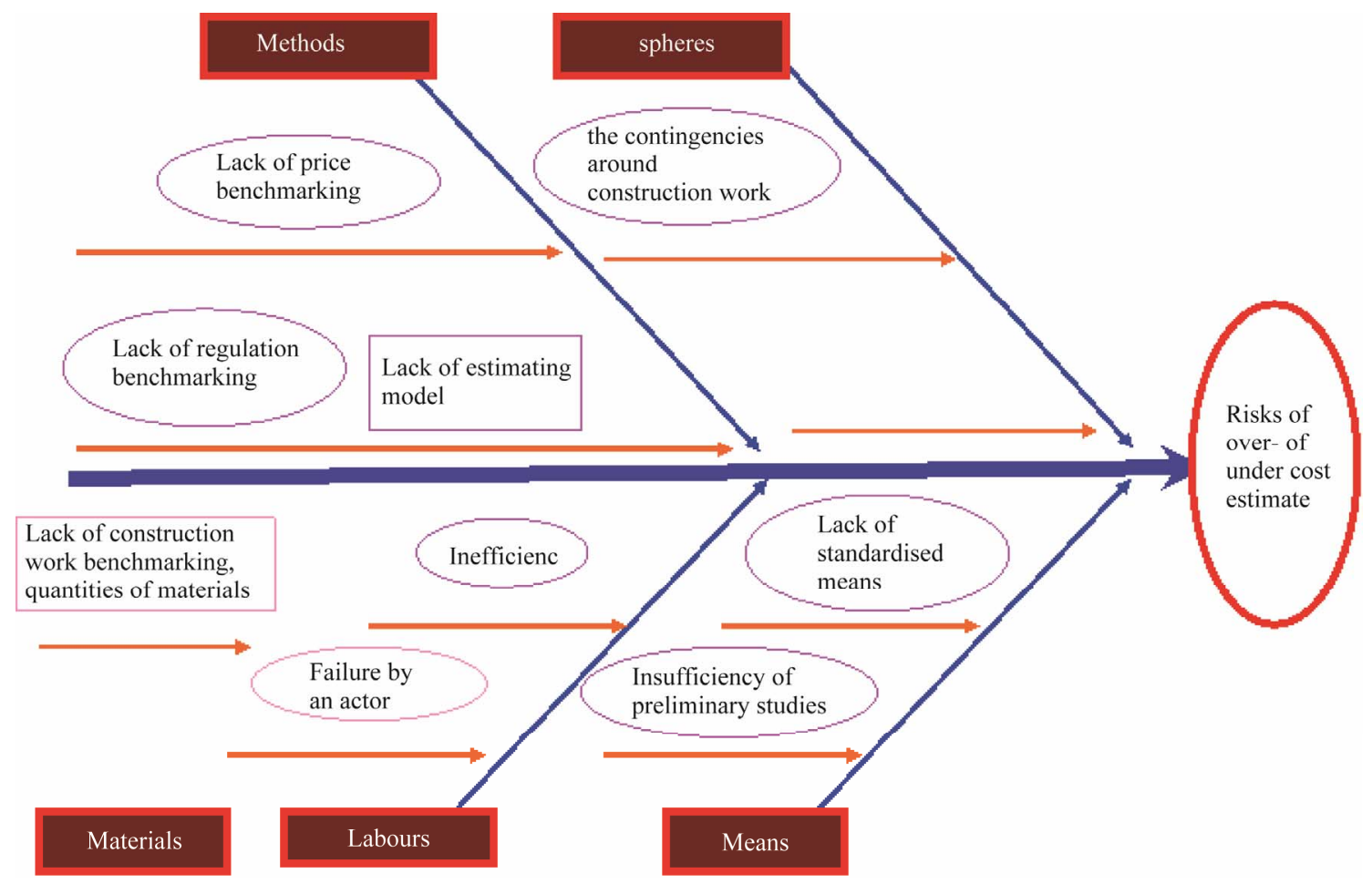

Diagram 1. The causes of Risks of over or under cost estimate.

gress of construction project; the estimates made by companies are most of the time established hastily because they have to make a big number of offers to make a deal it is worth noting that the multiple number of participating parties in building sector, the new construction technologies and innovations give a room to complexity and uncertainties in establishing estimates for projects.

The common practise nowadays in drawing up budget estimate of construction building project is done by the client and the company, the process is mainly done on the basis of two approaches: It is whether according to the cost of $m$ built or on the basis of prices of similar works of a project.

In the first method, the established estimates are not precise since the buildings found around construction sites are not identical, consequently, the cost of a square meter built is whether over- or underestimated.

The use of second method requires the management of cost per unit; it ought to be inspired continuously by the experience obtained through recent construction sites. The existence of unrealistic unit costs will not guarantee an accurate estimate of project costs.

The aim of this work is designing cost estimation model of a construction project. To achieve this aim, the following points are to be applied:

First, an analysis of the main existing cost estimate models and defining their advantages as well as their drawbacks in order to have them compared and focus on the one that will be used in construction project of the present work.

Second, defining the multiple components of construction project cost, in fact, each price consists of many elements, so before making any calculation of whatever price (purchase price, cost price...), one have to make a list of the components of price and then make their estimates.

Then emphasis is to be put first on the important estimate phases in construction project and later on common relationships, another area to be emphasized here is the importance of taking charge of the project by software management for building a construction cost estimating model that is tested in a real case study.

This paper is organized as follows: Section 1 deals with the previous studies on the causes of overestimate or underestimate of costs in construction projects; Section 2 explains the cost estimate models and elementary components to determine the estimate of a construction project. Section 3 discusses the findings and Section 4 presents the conclusions.

\section{Literature Review}

Various articles and studies have been conducted internationally on the causes of in construction projects. Kaming et al. [6] studied the causes of over- or underestimate of 31 sky-scrapers costs in Indonesia. She confirmed that the costs overruns often occur and are considered to be more important than deadline slippage; she also cited the main causes of cost overruns: increase due 
to inflation, the underestimate of equipment costs and the level of complexity of the construction project. The causes related to time overruns are: design changes, low productivity, inadequate planning, and resource shortages. AlMomani [7] in his survey on 130 public projects in Jordan pointed out that the main causes of delay are: poor project design, climate, poor site management, delay in delivery, economic situation and the amendments. He recommended that managers of public projects take the necessary time to start carrying out thorough studies by using real quantitative data in order to formulate pertinent terms before starting to attribute the said project. The study also suggested that special attention be given to industrialists in the field of construction to reduce the purchasing costs. Consequently, the delays are essentially due to poor contracters' productivity. Toor and S. O. Ogunlana [8] and Saleh Al Hadi Tumi et al. [9] believed that poor planning and lack of communication are the principle causes of deadline slippage in construction projects in Libya. Ogunlana et al. [10] noticed that time and cost overruns in construction projects of sky-scrappers in Bangkok and Thailand resulted from three factors: lack of infrastructure, default in payment by both customers and consultants, and contractors incompetence; they recommended that managers and associations specializing in the field of construction make more efforts to streamline and build the infrastructure which would allow easy supply of materials and boost efficiency in construction field.

Researchers have examined and identified the causes of cost overruns in construction projects (Table 1) and confirmed that most causes fall properly to firms by $51 \%$ and $30 \%$ to the project manager while $90 \%$ of these causes are related to the internal organization of involved parties.

\section{Cost Estimating Methods and the Elementary Components to Determine the Estimate of a Construction Project}

\subsection{The Cost Estimating Methods}

The estimates are made by humans and not by tools, the tools are means used by the analysts while reliable expert systems that can estimate costs are still unfound.

All estimates are based on comparisons. They are based on data base of the company. A handbook on costs that may allow the creation of a data base related to its activity still does not exist. In order to estimate, technical knowledge of context, tools, products, technologies and used means of production must be acquired. There are a number of estimating methods differentiated mainly by the level of precision that is desired in the results.

This includes:

- The analytical method
- Parametric method

- Analogy method

A method is not used randomly, there must be a coherence of the information obviously available, it is worth considering the progress of the project and what may requires the method to start functioning.

\subsubsection{Analogy Method}

\subsubsection{General Principle}

The analogy method of cost estimating functions by comparing the proposed project to previously similar completed projects where the cost and the functional definition is known.

By comparison, a sound judgment must be reached through the characteristics of two completed projects. This judgment must be quantified in a way that can be translated in terms of cost. The method must reduce the maximum of subjectivity.

The principle of this method is to implement an extrapolation of similar cases (source case) and of present case (target case). The source cases are extracted by the historical databases of the project.

The structure of the target case can be different from the source case. The case basis must be enriched continuously by new treated cases.

\subsubsection{Conclusion on Analogy Method}

It is worth stating its weaknesses since the use of the Analogy method gives rise to certain concerns.

a) It leaves room to subjectivity. Such observation is largely tempered by the fact that we put our trust on a detailed level limited enough in comparison with completion that is finished and known;

b) It supposes that the comparisons made are valid, such fact leads.

One to seek recent projects due to the need to keep pace with rapidly developing technologies, however, this is not always attainable on the one hand, on the other hand, the diversity of projects stands an obstacle to find close completions to standardized data on the other hand.

c) It implies that the development and production logics have to be the same to be able to assess those which are different; this is a serious obstacle in the measuring where an advanced level of estimate is required for the study. However, there exist no magic methods that can avoid asking such kind of question!

In fact, this method provides in a timely and responsive manner accurate estimate with low costs if it is rigorously applied. It allows having rapid studies of sensitivity while working on coefficients of analogy. It can therefore be used as input for comparison of principles for solutions studied in the analysis of value. However, one must not expect extraordinary precision. 
Table 1. Identified deadline slippage causes in construction projects over the last two decades.

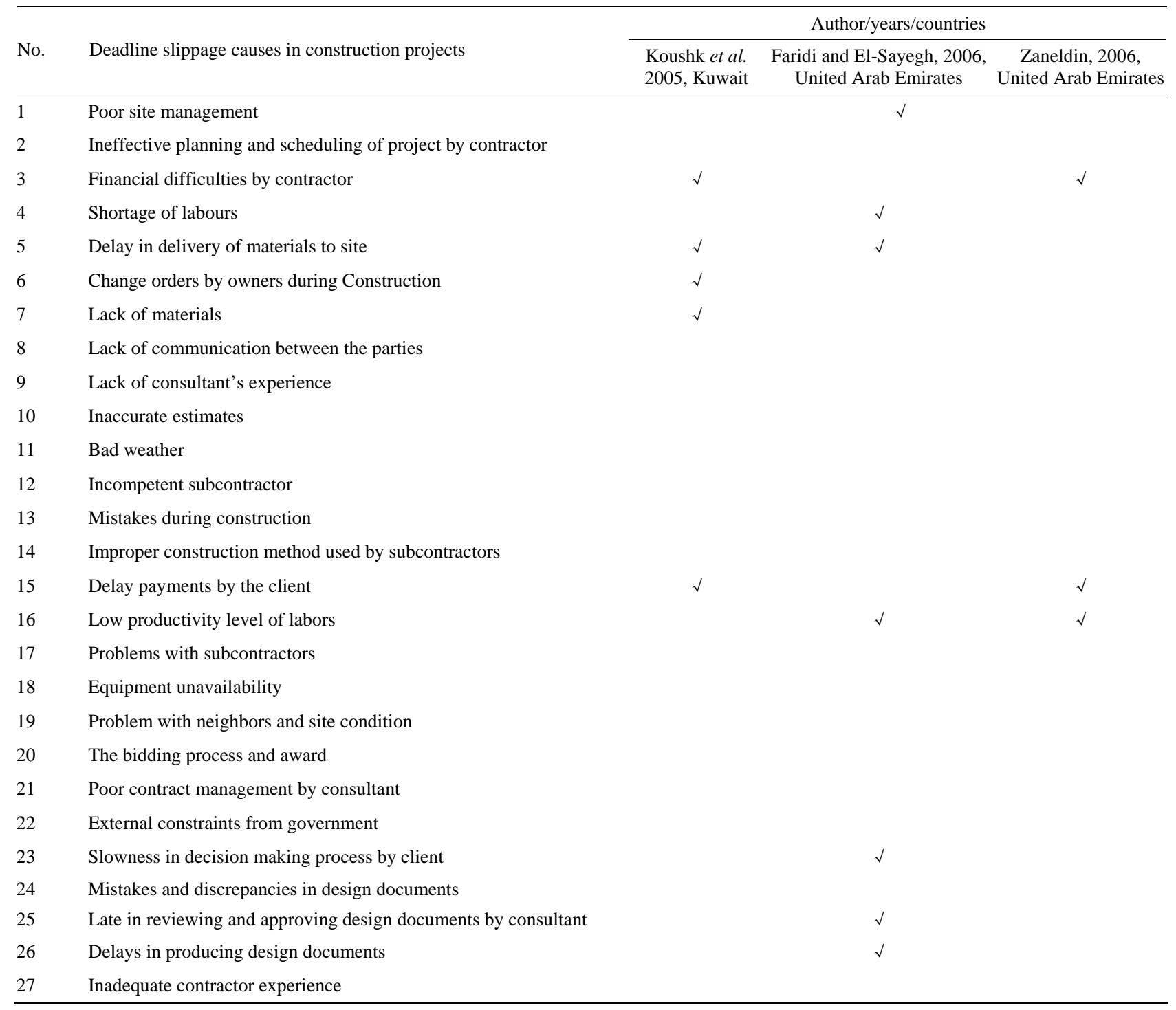

\subsubsection{Parametric Method}

\subsubsection{General Principle and Classification of Parametric Methods}

The cost estimating model used in design phase must be in coherence with the definition report of the project. It is then better to consider the concept of product architecture. We have not known yet how these products will be produced, but we can access a number of physical characteristics or parameters like the mass, the volume, the energy absorbed or the number of input-output. This is obtained for information purposes at the Beginning of development phase.

The parametric estimate has been constructed specifically to create from these parameters the costs to estimate. We must go from high techniques characterising the product and owned by the design engineer to economic data necessary for management.

Two main types of parametric methods are to be highlighted; they differentiated both by their design and usage.

a) The cost list;

b) The statistical models or cost estimates formula.

What to be concluded is that this method involves more complex calculations than the analogy method.

It only works on family products (or projects) of identical structure differing only in size. The calculations are automated on a spreadsheet such as Excel. The use of the application of parametric assessment can be within reach of an unskilled operator .On the contrary, the development of cost estimation formula is complex and requires an expert experienced in statistical calculation.

3.1.2.2. Conclusion Sur la Méthode Paramétrique It involves more complex calculations than the analogy 
method. It only works on family products (or projects) of identical structure differing only in size. The calculations are automated on a spreadsheet such as Excel.

The use of the application of parametric assessment can be within reach of an unskilled operator. On the contrary, the development of cost estimation formula is complex and requires an expert experienced in statistical calculation.

\subsubsection{The Analytical Method}

\subsubsection{General Principle}

The analytical method is the oldest, the most classic and the most widespread among other cost estimating methods. It requires very detailed information on the product to encode and on its development process. In its most complex form, it decomposes each activity into elementary tasks where the time is known. This method makes it possible to calculate the actual cost of past achievements and to build up a data bank.

The projects that have already been completed must be a source of experience for better anticipation and management of costs and risks of a new project.

\subsubsection{Conclusion on Analytical Method}

It is worth stating that this method permits to have precise estimate of costs. However, it requires much detailed information on both the product and tools used in a given operative range. The analytical method is therefore focused on as being chosen to be the subject of our studies although it requires the manager to be rigorous, since it is more detailed than others and it does not represent any subjectivity.

\subsection{The Basic Components of a Study of the Cost of a Construction Project}

\subsubsection{The Flat Costs}

These costs are also called direct payments or disbursements.

Flat costs are comprised of unit tasks, each contain some or all of the following resources: manpower production, supplies, equipment, subcontractors.

These expenditures are termed "flat" because their value is not weighted by any surcharge coefficient.

\subsubsection{Work Site Costs}

These costs constitute all six mass budget, they are as follows: labor site costs, supplies, assigned and non-assigned equipment; subcontractors and operating costs.

\subsubsection{The Total Disbursement}

According to the common relationships, the total disbursement is the sum of flat costs and building site costs. This is the total budget put at the disposal of the site manager to perform the work with good practice.

The total disbursement is also called cost of production, expressed in terms of value, it allows by a rule of three to get directly the amount of duty free sales, and then the coefficient for study, called K1, expressed in terms of value, it allows to calculate first K1 and amount of tax free sales. The results are naturally consistent. The total disbursement will be managed by the site manager.

\subsubsection{Special Costs}

Chronologically, these costs come after the building site costs. They are also called market fees.

These charges will not be managed by the building site and don't make a part of overheads since they are related to a specific case; they are most of the time costs that are charged to a work site which comprises:

\subsubsection{Overhead}

Overheads are necessary costs for the proper functioning of the company, it is not possible to disaggregate and allocate a precise production: administration, organization, management.

\subsubsection{Cost Price}

It is the total disbursement sum + special costs + overheads, that is to say the costs of all expenses of a project.

\subsubsection{Margin and Risks}

\subsubsection{Gross Margin}

The amount of gross margin brings together the total expenses resulting in the total disbursed (the cost of production).

\subsubsection{The Net Margin}

The amount of net margin is the difference between before-tax sale amount and cost price amount.

\subsubsection{The sales price excluding VAT}

It is the cost price plus a variable margin.

This margin is decided depending on information that is generally subjective. The sum of tax-free sales of the year represents the turnover of the firm. It is an important element that characterizes a business.

The increase of the Flat costs of work site by the coefficient C1 allows passing directly of the Cost price at Sale price (See Figure 1).

\section{Result: Developed Estimating Cost Model of Construction Project}

The constructed model (Figure 2) is based on analytical estimate method, it allows an ordered and thoughtful breakdown of the works, and it is also based on common relations that exist between the enlisted costs. It takes 


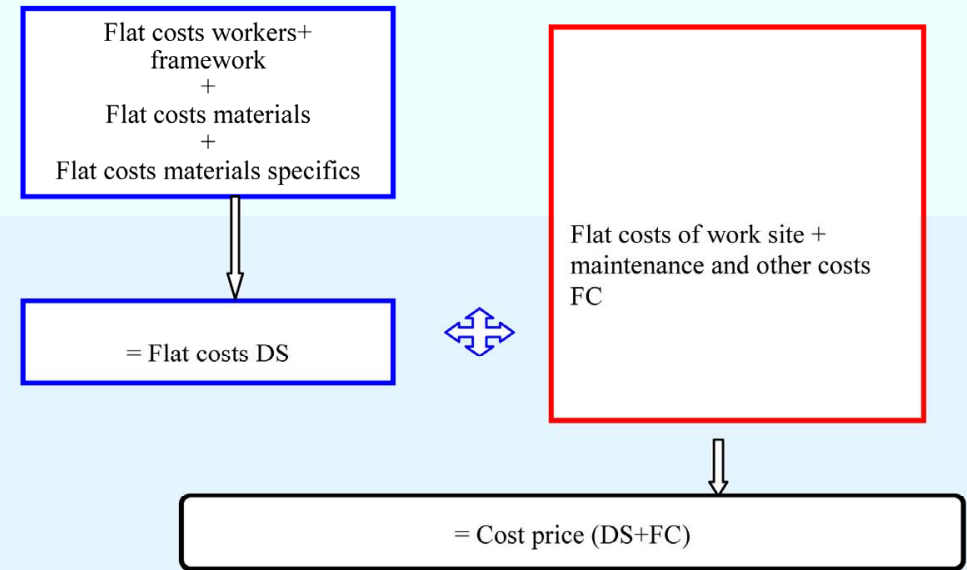

With $\mathrm{K}=($ Expenses of siege, the financial expenses and of assurance $)=13 \%$

$\mathrm{PV}=$ Sale price $($ estimation $)=(\mathrm{DS}+\mathrm{FC})^{*} \mathrm{C} 1$

Figure 1. Common relationship between the various expenses.

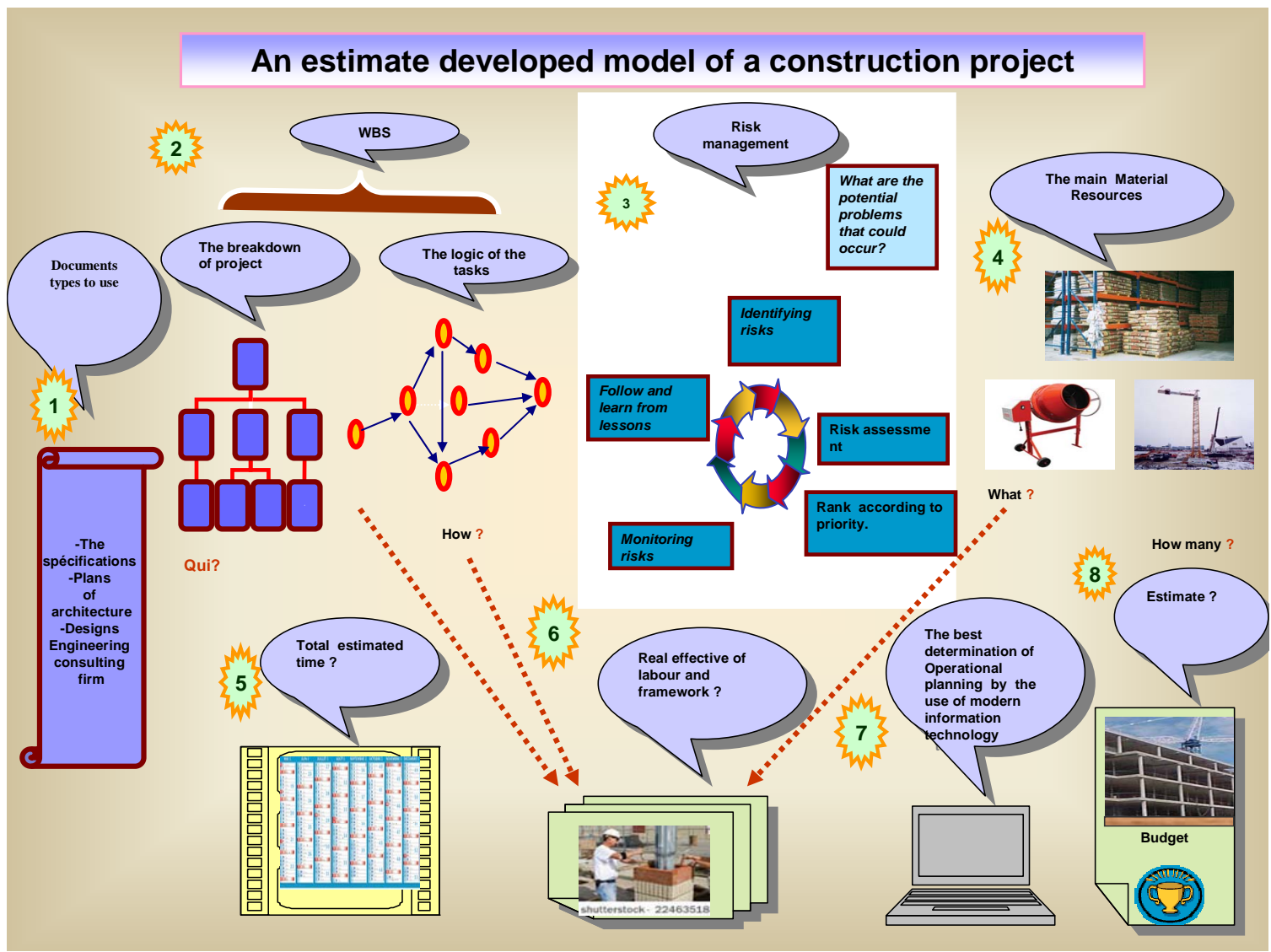

Figure 2. Developed model of cost estimating model. 
into consideration risk management, contractual deadline respect and it resorts to computer support. In addition, it is a model that requires very detailed information of the product to estimate as well its completion process, there must be also a deep knowledge of the exact structure of the product and detailed description of works. The model seeks to enhance each activity separately and to breakdown each activity into elementary tasks where the run time is known thanks to projected time unit.

The presented model highlights the various expenses taken into account for cost after having them classified into two categories: Directly and indirectly related to production.

The model serves to compile the costs, direct and indirect, necessary to project completion and according to the adopted planning in order to set up the budget necessary enough to project completion.

The model is based on data thoroughly examined where data processing is highly facilitated by appropriate software to allow the rationalization of expenses related to the allocation of resources to activities and to identify and resolve problems of under or overuse of resources and to create simulation planning in order to meet the contractual deadlines.

The model is presented as: (see Figure 2)

The proposed model for cost estimate of construction works is made up of eight stages:

The utilization of various types of documents necessary for cost estimate:

- Works break-down structure;

- Risk management;

- Determining equipment in need necessary to the works on site;

- Determining the overall scheduled time and contract period;

- Determining the real number of labour necessary to the work on site and management personnel;

- Determining the best operational planning resorting to data processing;

- Determining the cost estimate of a construction project.

The studied model has been tested on a construction project of administrative buildings in order to get the fixed estimate compared with the aid of set model and of the ones developed by the project manager and the company, the aim of this is to realize the importance of the differences so as to judge the reliability of estimates set up without and with the model.

Implementing this model has permitted the administration:

- To set up the estimate planned by the Article 4 of the decree related to public procurement;

- Determining the specifications and execution time in the course of an order form on development work according to the article 75 of the same decree;

- To control the estimate upstream.

In fact, the comparison of estimates has allowed seeing variation between the company's offer and the estimate determined by the model examined by the present paper.

The present model can form a basis for tender offer commission to:

- Assess and evaluate the technical offers according to Article 36 of the decree (meeting specifications required under the regulation)

- Be able to study costs indicated in Price Schedule

- To make simulations (Figures 3 and 4).

This figure shows the financial impact according to the production process. In fact, choosing ready-mixed concrete is seen to cost more in comparison with in-situ concrete.

This schema shows the budget percent of flat costs compared to the overall budget in building project.

\section{Study Case: The Construction Project of Administrative Building R + 4 Lot: Structural Work}

In this essay, the case treated here is the construction project of administrative building $\mathrm{R}+4$ lot: structural work, it Seeks to compare determined estimate using an adopted model with those developed by the contractor and the company, this aims to realise The importance of variance in order to judge the reliability of the estimates made with and without the model. The adopted model then is to be applied as study cases at first, different estimates are to be compared later.

The methodology remains the same, the construction processes know changes which make it necessary to adapt the volume of hours worked, the composition of the material and unit costs of materials (for example: instead of having in-situ concrete, we will use ready-mixed concrete etc...).

\subsection{Determining Needs in Terms of Materials Necessary for the Completion of Works}

\subsubsection{The Numbers of Crane and Their Capacities (Lift Station)}

In this project, we are going to have $4,715.85 \mathrm{~m}^{2}$ of floor to pour in 7.5 months (the date of completion of the structure rises to $75 \%$ of the overall delay which is 10 months.

Bearing In mind that a crane reaches an average monthly production of $800 \mathrm{~m}^{2}$, so in this project we will have: $4715.85 / 7.5=628.78 \mathrm{~m}^{2} /$ month, resulting in a number of cranes of $628.78 / 800=0.79$, then a crane will be enough.

We will install the crane on the basis of concreting and manufacturing areas. 


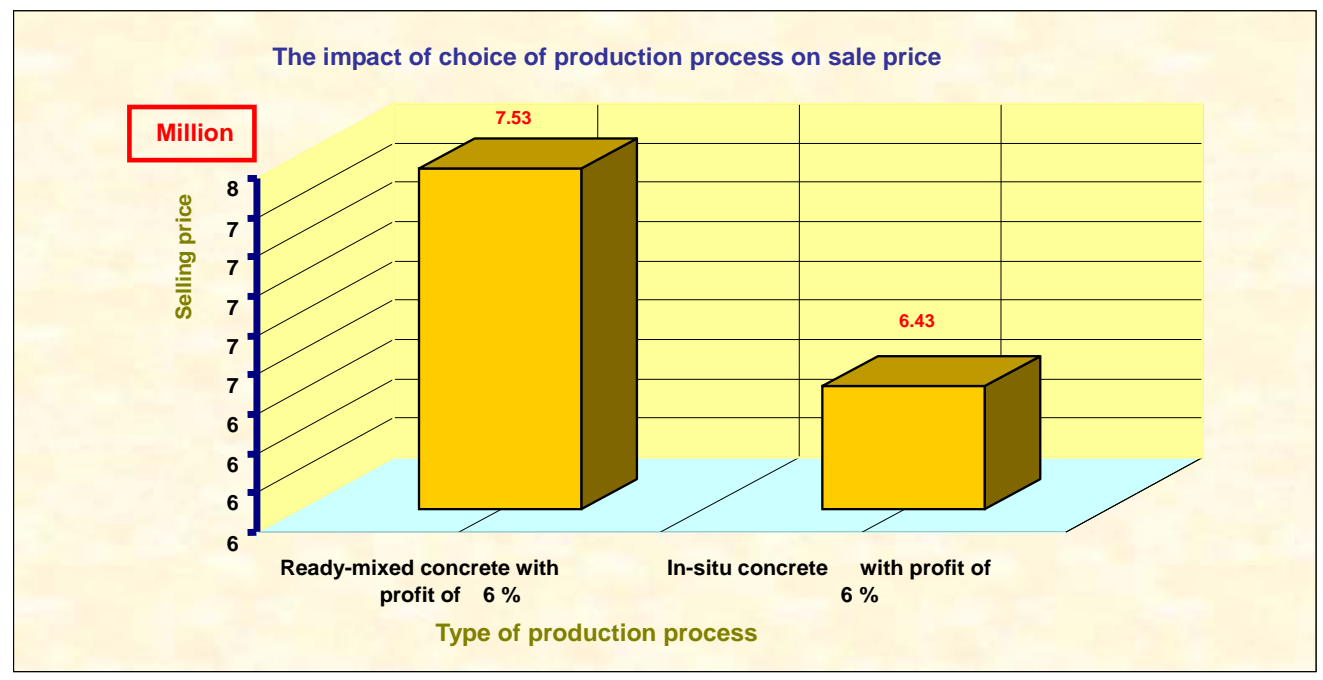

Figure 3. Production process impact on sales price.

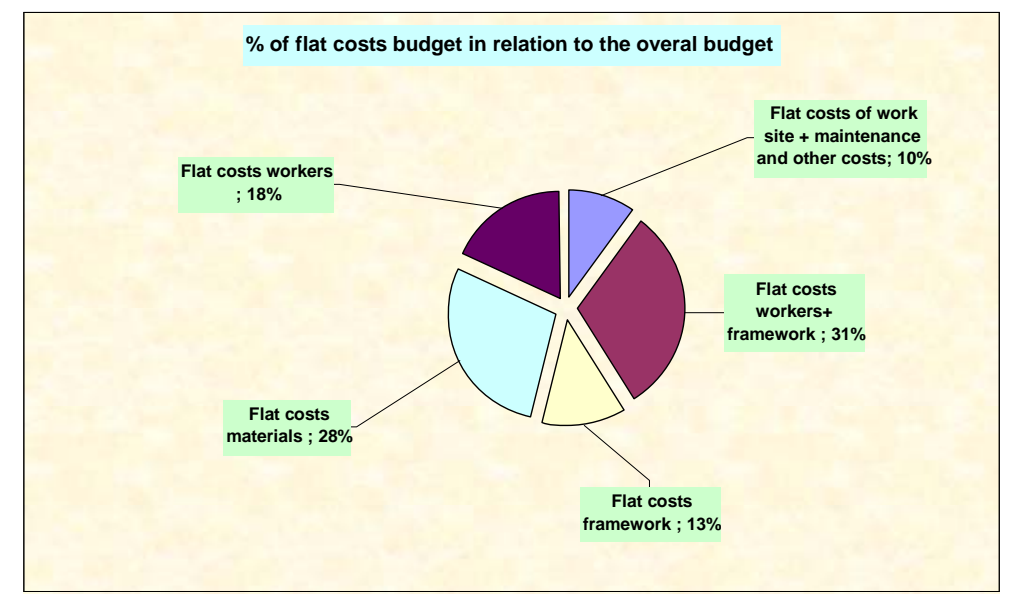

Figure 4. \% by flat cost budget with regard to the overall budget.

\subsubsection{Concrete Station}

Regarding the quotation (see CPS and price schedule on $\mathrm{CD}$, they are appended to this submission) we consider to have $1361.32 \mathrm{~m}^{3}$ concrete to pour for 7.5 months of structure, it is then a monthly return of order: $7.5=181.51$ $\mathrm{m}^{3} / \mathrm{month}$.

If we consider this, we will have: $181.51 \times 2=363$ $\mathrm{m}^{3} /$ month.

Or by day: $363 / 20=18.15 \mathrm{~m}^{3} /$ day.

And by hour: $18.15 / 5=3.63 \mathrm{~m}^{3} /$ hour.

So we will install 1 cement mixer of $750 \mathrm{l}$ in the vicinity of the crane.

\subsection{Determining the Total Estimated Time}

The total estimated time is directly linked to quantities of works to be completed (Table 2), but it is not linked to turnaround times required by the client. The labour time is reached by multiplying the unit time by the quantity to be completed.
Table 2. Total quantities of project hours.

\begin{tabular}{lc}
\hline Type of services & Number of hours needed for completion \\
\hline Structure & 53174.02 \\
Masonry + cement facing & 20722.60 \\
Earthworks + pipe & 4461.00 \\
Total project hours & 78357.62 \\
\hline
\end{tabular}

\section{Determining Delays}

Taking into regard that $78357.62 \mathrm{~h}$ as 7.5 months of contractual time, we would get the following delays (Table 3).

Delay for each type of service $=$ Number of hours Needed for completion $\times 7.5$ (the contractual time)/Total $\mathrm{h}$ project.

These delays are determined while considering that a team of $\mathrm{n}$ workers will work continuously from the beginning to the end. 
Table 3. Delay (by day) for each type of service.

\begin{tabular}{cccc}
\hline Type of services & $\begin{array}{c}\text { Number of hours } \\
\text { needed for completion }\end{array}$ & $\begin{array}{c}\text { delay (in months) for each type of service }=\text { Number of hours } \\
\text { needed for completion } \times \text { 7.5 (the contractual time)/Total h project }\end{array}$ & $\begin{array}{c}\text { Delay (by day) for } \\
\text { each type of service }\end{array}$ \\
\hline Structure & 53174.02 & 5.09 & 137.42 \\
Masonry + cement facing & 20722.60 & 1.98 & 53.55 \\
Earthworks +pipe & 4461.00 & 0.43 & 11.53 \\
Total project hours & 78357.62 & 7.50 & 202.50 \\
\hline
\end{tabular}

\subsection{Determining the Real Effective of Workforces and Supervising Staff}

Determining the average effective of workforce (Table 4).

\subsection{Determining the Best Operational Planning to Meet the Specifications Criteria}

Using Ms project software for the project to be taken over

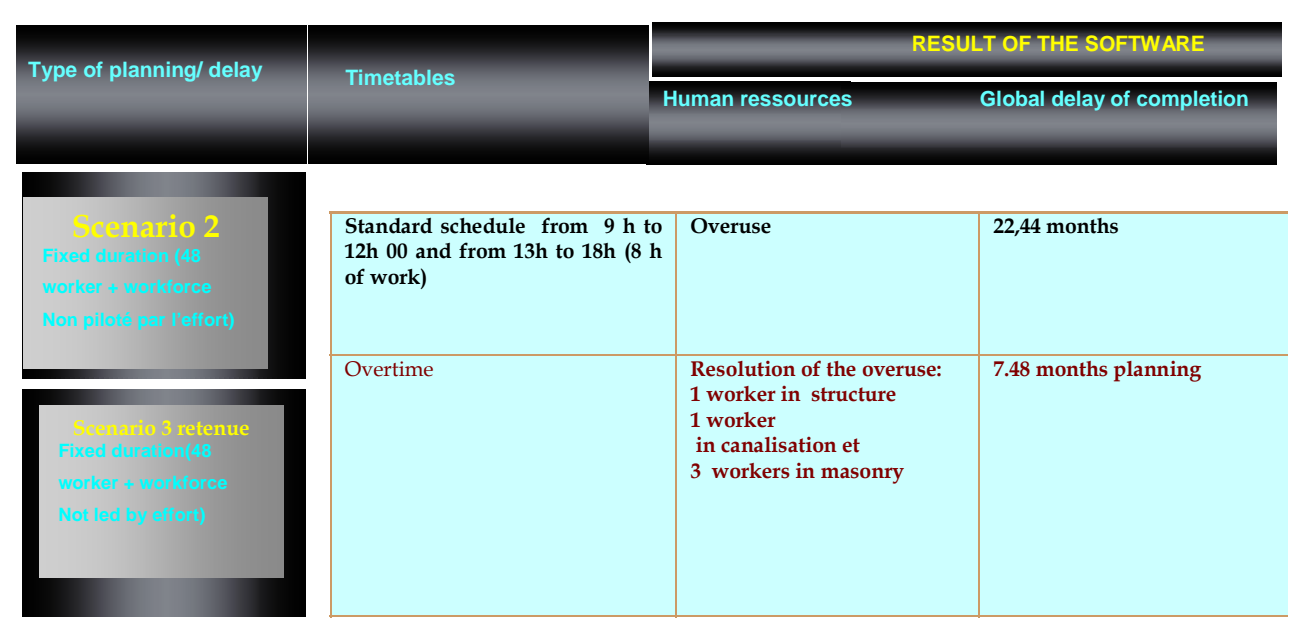

\subsection{Estimation}

The cost estimate of a construction project is none other than the sales price that can be determined by common relations between various expenses

\subsubsection{Determining Flat Costs}

For the purpose of automating the calculation of flat costs, the creation of spreadsheet is enough according to the integrated formula as indicated by the following Table 5 :

\subsubsection{Calculating Sale Price (Estimation)}

Calculate the sale price on the study case is as follows (See Figure 5).

We fulfil our primary purpose by consolidating all the results achieved nationally and internationally in terms.

Of cost estimating methods, of cost price calculating, of common relations of various expenditures.

Of project management using computer program related to project management, it is our goal by this to construct a model that can reach the most realistic cost estimating of a construction project.

In fact, after having an analysis of the advantages and drawbacks of cost estimating methods, one method has been chosen and adopted for determining cycle times and after studies of the components of construction project price, the main components as well as the common relations between expenses have been taken into consideration.

After determining the shortcomings of cost estimating methods, it is worth considering the contractual delay for the completion of the project and also the features of Ms Software project.

This study requires a variety of investigations:

a) Scientific, for mathematical knowledge based of calculation of quantities and of price study;

b) Technical, by the knowledge of materials as well as their usage conditions;

c) Practical, by the observation qualities and necessary deduction to the choice of quantities;

d) With rigour, for pricing the unit sales price excluding VAT of infrastructure components.

This method can serve as a basis for the administration to:

e) Establish its own estimate for the completion of construction services;

f) Assess and compare the offers proposed by the com- 
Table 4. The average number of labour.

\begin{tabular}{|c|c|c|c|c|}
\hline Type of services & $\begin{array}{c}\text { Number of hours } \\
\text { needed for completion }\end{array}$ & $\begin{array}{l}\text { delay (in months) for each type of service = } \\
\text { Number of hours needed for completion } \\
\times 7.5 \text { (the contractual time)/Total h projet }\end{array}$ & $\begin{array}{l}\text { Delay (by day) for } \\
\text { each type of service }\end{array}$ & $\begin{array}{l}\text { Effective of workforce }= \\
\text { Total time of workforce } \\
\text { (by hour) } /(8 * \mathrm{Dj})=\mathrm{N}\end{array}$ \\
\hline Structure & 53174.02 & 5.09 & 137.42 & 48 \\
\hline Masonry + cement facing & 20722.60 & 1.98 & 53.55 & 48 \\
\hline Earthworks + pipe & 4461.00 & 0.43 & 11.53 & 48 \\
\hline Total project hours & 78357.62 & 7.50 & 202.50 & 48 \\
\hline
\end{tabular}

Table 5. Formulas to calculate automatically the flat cost.

\begin{tabular}{|c|c|c|c|c|c|c|c|c|c|}
\hline \multicolumn{2}{|l|}{ Unit prices } & & $U P$ & $U P 1$ & \multicolumn{2}{|r|}{$U P 2$} & \multicolumn{2}{|r|}{ UP3 } & \multirow{4}{*}{$\begin{array}{c}\text { Deb. sec total en dhs TTC }= \\
\text { DST }\end{array}$} \\
\hline \multirow{3}{*}{$\begin{array}{c}\text { Unit } \\
\text { Designation } \\
\text { Of infrustructure } \\
\text { UOe }\end{array}$} & \multirow{3}{*}{$\mathrm{U}$} & \multirow{3}{*}{$\mathrm{Q}$} & \multirow[t]{2}{*}{ Designation } & MO & \multicolumn{2}{|r|}{ M1 } & \multicolumn{2}{|r|}{ M2 } & \\
\hline & & & & DS1 & Qm1 & DS2 & Qm2 & DS3 & \\
\hline & & & $\mathrm{NH} \mathrm{O}=\mathrm{TU}$ & dhs TTC & $\mathrm{M}^{3}$ & dhs TTC & $\mathrm{M}^{3}$ & dhs TTC & \\
\hline UOe1 & $\mathrm{M}^{3}$ & Q1 & NHO1 = TU1 & Q1*NHO1*PU1 & Q1M1 & Q1M1*NHO1*PU2 & Q1M2 & $\begin{array}{c}\text { Q1M2* } \\
\text { NHO1*PU3 }\end{array}$ & $\begin{array}{c}\text { Q1*NHO1*PU1 + } \\
\text { Q1M1*NHO1*PU2 + } \\
\text { Q1M2*NHO1*PU3 = DST1 }\end{array}$ \\
\hline UOe2 & $\mathrm{M}^{3}$ & Q2 & NHO2 = TU2 & Q2*NHO1*PU1 & Q2M1 & Q2M1*NHO2*PU2 & Q2M2 & $\begin{array}{l}\mathrm{Q} 2 \mathrm{M} 2 * \mathrm{NH} \\
\mathrm{O} 2 * \mathrm{PU} 3\end{array}$ & $\begin{array}{c}\mathrm{Q} 2 * \mathrm{NHO} 1 * \mathrm{PU} 1+ \\
\mathrm{Q} 2 \mathrm{M} 1 * \mathrm{NHO} 2 * \mathrm{PU} 2+ \\
\mathrm{Q} 2 \mathrm{M} 2 * \mathrm{NHO} 2 * \mathrm{PU} 3=\mathrm{DST} 2\end{array}$ \\
\hline UOe3 & M2 & Q3 & NHO3 $=$ TU3 & Q3*NHO1*PU1 & Q3M1 & Q3M1*NHO3*PU2 & Q3M2 & $\begin{array}{l}\text { Q3M2*NH } \\
\text { O3*PU3 }\end{array}$ & $\begin{array}{c}\text { Q3*NHO1*PU1 + } \\
\text { Q3M1*NHO3*PU2 + } \\
\text { Q3M2*NHO3*PU3 = DST3 }\end{array}$ \\
\hline UOe4 & $\mathrm{M}^{3}$ & Q4 & NHO4 = TU4 & Q4*NHO4*PU4 & Q4M1 & Q4M1*NHO4*PU2 & Q4M2 & $\begin{array}{l}\mathrm{Q} 4 \mathrm{M} 2 * \mathrm{NH} \\
\mathrm{O} 4 * \mathrm{PU} 3\end{array}$ & $\begin{array}{c}\mathrm{Q} 4 * \mathrm{NHO}^{*} * \mathrm{PU} 4+ \\
\mathrm{Q} 4 \mathrm{M} 1 * \mathrm{NHO} 4 * \mathrm{PU} 2+ \\
\mathrm{Q} 4 \mathrm{M} 2 * \mathrm{NHO} 4 * \mathrm{PU} 3=\mathrm{DST} 4\end{array}$ \\
\hline & & & Tot & Il flat cost & & & & & $\begin{array}{c}\mathrm{DSTI}+\mathrm{DST} 2+\mathrm{DST} 3+ \\
\text { DST4 }=\text { DSTT }\end{array}$ \\
\hline
\end{tabular}

With: PU: Unit price; U: Measuring unit; UOe: Infrastructure component unit; NHO1 = TU1: Time unit corresponding to the working time of an average worker; Q: Estimated quantity of infrastructure component unit; M1: Materials making up the infrastructure component unit Matériaux composant; QM1: Quantity of material (M1) making up 1 (UOe1) infrastructure component unit; DS1: These expenses are also called flat costs = Expenditure in productive employees + the purchase of materiel + Specific material; These expenses are termed "flat" because their value is not weighted by any surcharge coefficient; DST: Is the sum of flat costs $=$ DST1 + DST2 $+\ldots$ With: DST1 $=$ DS1 (UOe1) + DS2 (UOe2).

pany with estimates established by the administration or the architect in the choice of the lowest-priced bidder and also for the study of unit prices contained in the schedules price.

This method will make it possible to determine the necessary resources to carry out each project service, aiming to judge the technical offers of bidders proposing a list of human and material resources.

The adopted method allows determining the human (workers, supervisory staff) and material resources required for the completion of construction project. It is worth noting that we have applied this method in other projects of great consistency and we have come to relevant results. However, the benefits realization of methodology of cost estimating requires special attention to all stages of the contract.

A specific monitoring must be provided from the initial cost investment stage to the attribution one.

The estimate of structures costs can't be close to reality unless the various tasks are to be scheduled depending on the delay required by the administration and with the support of human and material resources, in fact, establishing a good determining of estimate is an important condition for planning a project.

\section{Conclusion}

Our goal is to consolidate the achievements and gains that exists both nationally and internationally in terms of cost estimating methods and calculation of sales price, in 


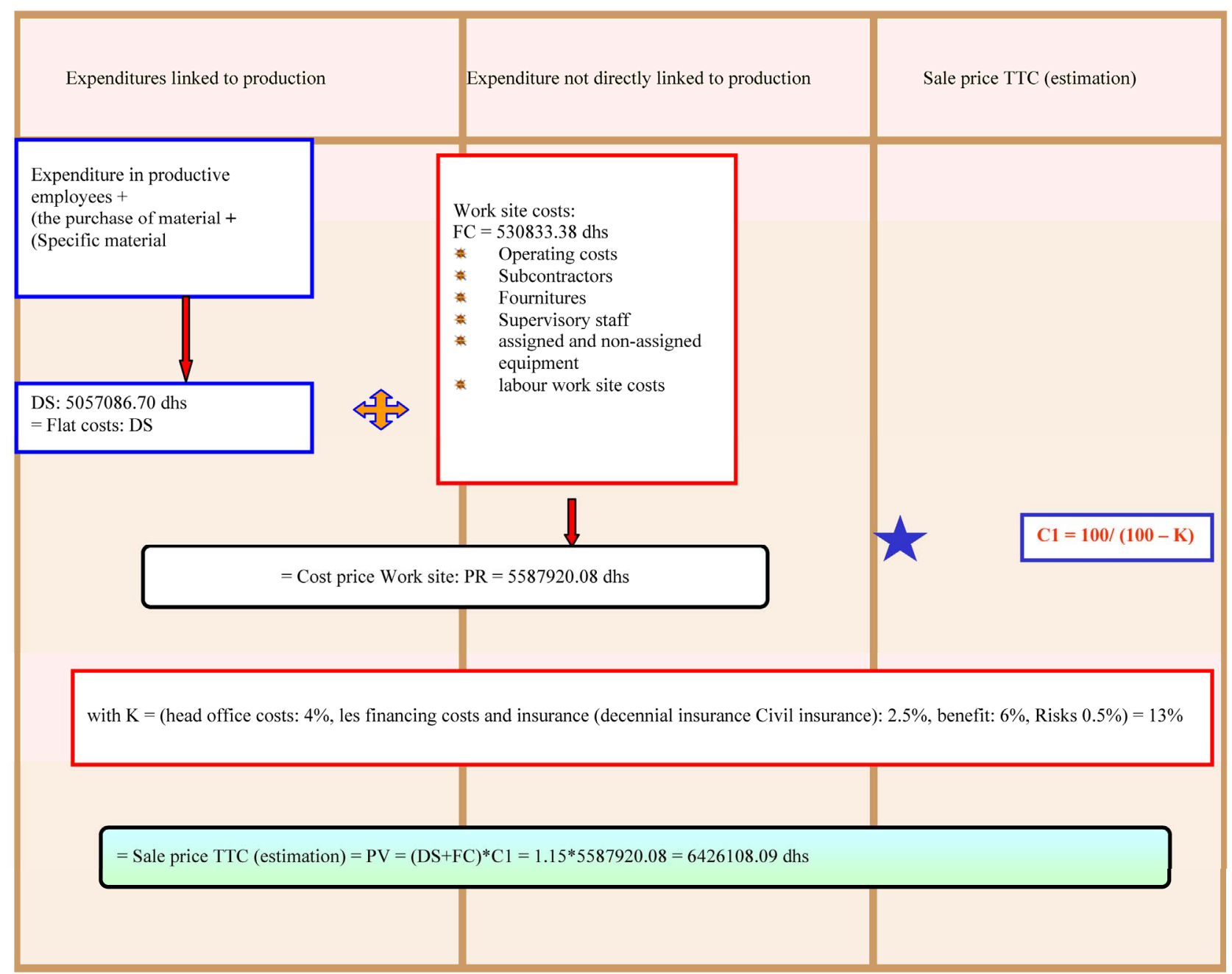

Figure 5. Cost price calculating process.

terms of common relationships between expenses, in terms of project management and computer contribution in project management tools. The aim of this is to build a model that can approach cost reality of a construction project.

Following an analysis of the advantages and disadvantages of cost estimating methods, a method is in the process of selection to identify the unit times.

According to studies of price components of a construction project, the main components as well as the common relationships between costs have been taken into account. It is worth considering the contractual delay for project completion as well as management concepts and management software functionalities of projects after identifying the shortcomings of cost estimating methods.

Another point to be noted is that we have implemented this method on other projects of great consistency and we have arrived at relevant results. However, the benefits realization of cost estimate of construction projects requires a particular attention to be paid to all stages of life of the contract, and a specific monitoring should be followed from the initial capital cost stage.

\section{REFERENCES}

[1] J. O. Ajanlekoko, "Controlling Cost in the Construction Industry,” Lagos Q. S. Digest, Vol. 1, No. 1, 1987, pp. 812.

[2] D. W. Chan and M. M. Kumaraswamy, “A Comparative Study of Causes of Time Overruns in Hong Kong Construction Projects," International Journal of Project Management, Vol. 15, No. 1, 1997, pp. 55-63. doi:10.1016/S0263-7863(96)00039-7

[3] A. S. Faridi and S. M. EL-Sayegh, "Significant Factors Causing Delay in the UAE Construction Industry," Construction Management and Economics, Vol. 24, No. 11, 2006, pp. 1167-1176. doi:10.1080/01446190600827033

[4] G. O. Jagboro and A. A. Albinu, "The Effects of Construction Delays on Project Delivery in Nigerian Construction Industry," International Journal of Project Management, Vol. 20, No. 8, 2002, pp. 593-599. 


$$
\text { doi:10.1016/S0263-7863(02)00028-5 }
$$

[5] K. Gkritza and S. Labi, "Estimating Cost Discrepancies in Highway Contracts: Multistep Econometric Approach,” Journal of Construction Engineering and Management, Vol. 134, No. 12, 2008, pp. 953-962. doi:10.1061/(ASCE)0733-9364(2008)134:12(953)

[6] P. Kaming, P. Olomolaiye, G. Holt and F. Harris, "Factors Influencing Construction Time and Cost Overruns on High-Rise Projects in Indonesia," Construction Management and Economics, Vol. 15, No. 1, 1997, pp. 83-94. doi:10.1080/014461997373132

[7] A. H. Al-Momani, "Construction delay: A Quantitative Analysis,” International Journal of Project Management, Vol. 18, No. 1, 2000, pp. 51-59. doi:10.1016/S0263-7863(98)00060-X
[8] S. U. R. Toor and S. O. Ogunlana, "Problems Causing Delay in Major Construction Projects in Thailand," Construction Management and Economics, Vol. 26, No. 4, 2008, pp. 395-408. doi:10.1080/01446190801905406

[9] S. Al H. Tumi, A. Omran and A. H. K. Pakir, "Causes of Delay in Construction Industry in Libya," The International Conference on Economics and Administration, Faculty of Administration and Business, University of Bucharest, Buchares, 14-15 November 2009.

[10] S. O. Ogunlana, K. Promkuntong and V. Jearkjirm, “Construction Delays in a Fast-Growing Economy: Comparing Thailand with other Economies", International Journal of Project Management, Elsevier, Vol. 14, No. 1, 1996, pp. 37-45. doi:10.1016/0263-7863(95)00052-6 